\title{
BIBTEX FOR THE ROMANIAN LANGUAGE
}

\author{
MARIAN MUREŞAN
}

\begin{abstract}
BibTeX was created by Oren Patashnik and Leslie Lamport in 1985 according to https://en.wikipedia.org/wiki/BibTeX and turned out to be a very useful software product. Nevertheless most of the present scientific paper in mathematics and computer science, and not only, are written in English. Our aim was to offer to the Romanian scientific paper writers a variant of the BibTEX whose output agrees with the Romanian language grammar.
\end{abstract}

\section{Presentation}

Many years ago I faced to the following issue: how to use the $\mathrm{AT}_{\mathrm{E} X} \mathrm{X}$ and

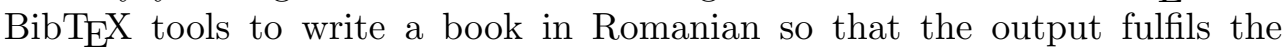
requirements of the Romanian grammar. The problem was the bibliography part since certain rules are not longer true. A trivial example is the following: in Romanian there no word and but instead of it there is the word şi.

There in 1996 we started to study how BibTEX is constructed and how can it be modified. As a result of this attempt a first version of the Romanian $\mathrm{BibT}_{\mathrm{E}} \mathrm{X}$ was released at July 1st 1996. Later on two improved were performed and released at November 30th 1997 and February 9th 2009, respectively. Our package AMSP-MR1.BST accepts input according to the rules of BibTEX and supplies output with certain changes oriented to the Romanian language.

The latest version of our Romanian BibTEX is uploaded on the author's web site http://marianmuresan.wordpress.com. Obviously our product is free.

Faculty of Mathematics and Computer Science, Babeş-Bolyai University, 1 M. Kogălniceanu St., 400084 Cluj-Napoca, Romania

Email address: mmarian@math.ubbcluj.ro

Received by the editors: 2 May 2021.

2010 Mathematics Subject Classification. 97P40, 97R30.

1998 CR Categories and Descriptors. D.3.3 [Language Constructs and Features]: Modules, packages.

Key words and phrases. BibTEX. 